\title{
Deformation Evaluation of Solder Ball Joints by Electromotive Force
}

\author{
T. Kumazawa ${ }^{1, \mathrm{a}}$ and K. Kaminishi 2,b \\ ${ }^{1}$ Akita Prefectural University, Department of Machine Intelligence and Systems Engineering \\ 84-4 Tsuchiya-Ebinokuchi, Yurihonjyo, Akita, 015-0055, JAPAN, \\ 2 Yamaguchi University, Graduate School of Innovation \& Technology Management \\ Tokiwadai 2-16-1 Ube, Yamaguchi, 755-8611, JAPAN \\ aKumazawa@akita-pu.ac.jp, ${ }^{b}$ kaminisi@yamaguchi-u.ac.jp
}

Keywords: Deformation, Strain, Electromotive force, Strain energy, Solder joint

\begin{abstract}
Deformation measurements with a thermocouple were applied in a deformation test of solder joints. The thermocouple is effectively combined with a conventional testing machine. The lead-solder and non-lead solder joints were pulled and sheared. The load-displacement and electromotive force (Emf)-displacement curves can be continuously derived from the signals of a load cell and the thermocouple. The Emfs in tension were compared with that in shear. The maximum Emf value in tension was larger than the emf value in shear, which meant in weakness of the solder joint in shear. Fracture occurred at the interface between the copper layer pad and solder, and the obtained Emf is closely related to fracture at the interface. The maximum Emf value in the non-lead solder was smaller than the Emf value in the lead-solder.
\end{abstract}

\section{Introduction}

From an environmental viewpoint, lead containing solders are harmful to human beings and other living things, which is the reason lead-free solders and new technologies for electronic interconnections have been introduced. Possible alternatives for lead-free solders include Sn-Ag-Cu and Sn-Zn materials. On the other hand, due to increasingly higher degrees of integration, higher component densities and resulting higher production costs of packaging, more stringent reliability requirements are being imposed on soldering assemblies. Deformation evaluations of solder joints under shear and tensile loading are essential to assess solder joint reliability. However, deformation measurements of small and spherically shaped solder joints are difficult to make using conventional techniques. The strain energy change is caused by a deformation which has a small temperature change. This temperature change can be measured with a thermocouple; this presents a possible method for deformation measurements of small solder joints.

This paper describes the application of a thermocouple, i.e., an electromotive force technique, to the deformation measurements of small solder joints which are made of lead and lead free materials. This thermocouple technique was successively combined with a conventional testing machine. The tensile and shear tests were conducted and Emf data were measured during deformation of solder joints.

\section{Electromotive force technique}

Principle and arrangement for tests. The electromotive force technique involves measuring a small temperature change, which is caused by strain energy when the object is deformed [1]. The temperature change due to deformation is $2-3^{\circ} \mathrm{C}$ at most. Therefore, this small temperature change is measured by a thermocouple [2] based on the Zeebeck Effect. The thermocouple is composed of a combination of two different conductive material wires. From among possible thermocouple wire combinations, a copper wire - constantan wire combination is adopted because this is expected to have a large output and copper wiring is widely used in electric circuits on a substrate. Copper 
circuit wire must be used as one of the thermocouple wires, if the electromotive force technique is applied to an electric circuit substrate. The diameter of the copper and constantan wires used here is $0.1 \mathrm{~mm}$ and their length is about $60 \mathrm{~cm}$. Though two thermocouple wires are joined together at their ends in a conventional temperature measuring method, the object of measurement here, a solder ball joint, is sandwiched by the thermocouple wires in our proposed technique (Fig.1). The other non-bonded ends of the thermocouple wires are kept at $0^{\circ} \mathrm{C}$ by immersing them in an ice-filled container. A dummy solder joint with the thermocouple is placed near the testing solder joint to [3,4] compensate for the Emf which is caused by room temperature and electric noises. The compensated Emf is amplified, displayed on the oscilloscope and recorded on a personal computer.

The thermocouple wires were bonded with the solder ball by using low melting point solder at first. Next, the thermocouple wires are fixed to a testing machine. The constantan wire is successively fixed on a pulling (and also shearing) chuck heads (Fig.2). The constantan wire is fixed to both tops of the chuck to get good contact between the chuck and the solder ball, and together into a wire at a short distance form the chuck. The copper wire is attached to a printed wire, which connects to the solder ball joint on the substrate. When the chuck starts to grasp the solder ball joint, a circuit is achieved for the Emf measurement, as the copper wire - layer (copper) - solder ball - chuck constantan wire connections.

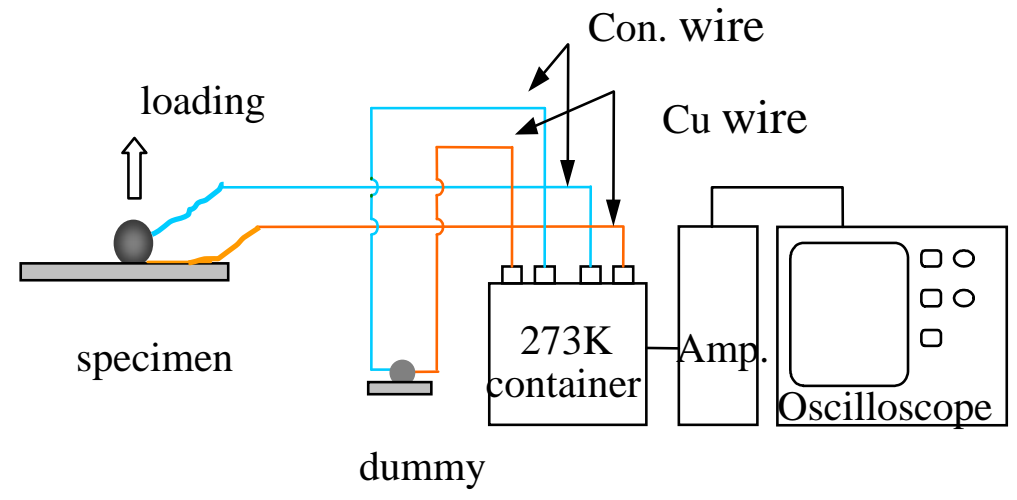

Fig.1 Schematic for Emf measurement for a thermocouple.

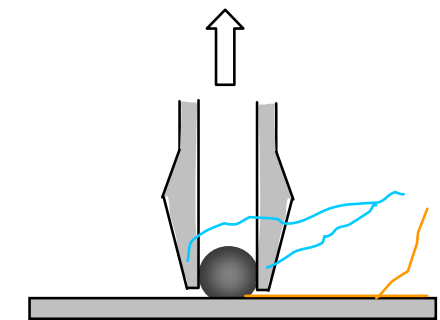

(a)

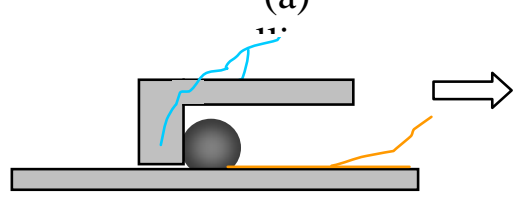

(b) shearing

Fig.2 Chuck with thermocouple

Solder ball joint sample and tests. The solder ball joint samples [3] are shown in Fig.3. They are made of Sn-37Pb (SP) and Sn-3.5Ag-0.75Cu (SAC) solder materials. There are 6 bonded balls on a board, which is made of FR4 substrate $(15 \times 30 \mathrm{~mm})$. The diameter of each bonded ball is about $0.6 \mathrm{~mm}$. The copper circuit line is wiring from the electric pad where the solder balls were bonded.

The solder ball joints are pulled by using a bond tester (DAGE, series 4000). The tester specification are as follows: force detector accuracy, $\pm 0.25 \%$ F.S.; tension speed, $0.1-7 \mathrm{~mm} / \mathrm{sec}$; maximum force, $10 \mathrm{Kgf}$ [4]. At first, a solder ball joint on the substrate is carefully positioned under the chuck and the substrate is fixed by a vacuum chuck. Next, tensile loading was started by closing the chuck around the solder joint. Noises were observed in the Emf data at first, which came from the chuck through the whole testing machine. Therefore, the chuck was isolated electrically using a Teflon plastic coating. Finally the Emf is possible to be measured while applying a tensile load.

The constantan wire is fixed at the top of the chuck and the chuck is made of hard steel. To investigate the effect on Emf generation because of the chuck, two set up configuration (with and without the chuck) were immersed in a silicon oil bath and gradually heated. The difference in Emfs was very small, so the compensation of Emf due to the chuck in a measuring circuit could be neglected in the data treatment. 


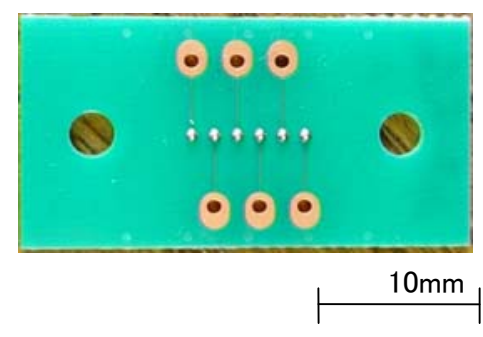

(a) Substrate

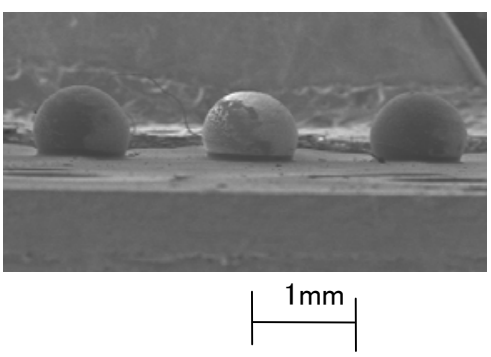

(b) Solder ball joints

Fig.3 Solder ball joint samples

\section{Deformation of solder ball joint by tensile loading}

Electromotive force in the SAC solder joint. The solder ball joints are pulled at speeds of $2 \mathrm{~mm} / \mathrm{s}$ and $4 \mathrm{~mm} / \mathrm{s}$ in tension. The Emf-displacement and load-displacement graph for SAC is shown in Fig.4 (a). The Emf is amplified in recording, but showed in a real $\mathrm{mV}$ unit without smoothing and filtering treatment. The signal noises in Emf are not small, but shown for better understanding of the generated real Emf.

The load increases gradually as displacement increases and reaches a maximum. This behavior suggests that the ball joint fractures within an elastic deformation. On the other hand, the Emf starts to decrease after a long delay for load increasing and reaches a minimum. The maximum of Emf is coincident with the maximum load and fracture point.

The time from start of loading to fracture is short, e.g. $0.5 \mathrm{~s}$, because the displacement speed is $2 \mathrm{~mm} / \mathrm{s}$. The ball joint is deformed at almost the thermal adiabatic condition as the deformation time is short (0.5s). When the solder joint is pulled, the joint neck might be deformed as in a volume expansion because shrinking in the radius direction is disturbed and elongated in the axial direction. The tensile deformation of the ball joint is elastic. Plastic deformation may be quite small, even if some plastic deformation occurs. The Emf decreases due to tensile elastic deformation and increases due to plastic deformation [5]. Therefore, the Emf decreases as the load increases. But the reason why the start time of the Emf decrease is delayed is not clear at present.

Emf obtained at a speed of $4 \mathrm{~mm} / \mathrm{s}$ in tension is shown in Fig. 4(b). The minimum value is smaller than that at a speed of $2 \mathrm{~mm} / \mathrm{s}$. The strain energy change seems to increase as deformation speed increases, because energy per unit time increases, even if the same deformation occurs. Furthermore, thermal dispersion decreases in a short time. Therefore, depending on the speed and thermal adiabatic state, the strain energy, i.e., Emf change, decreases as time decreases.

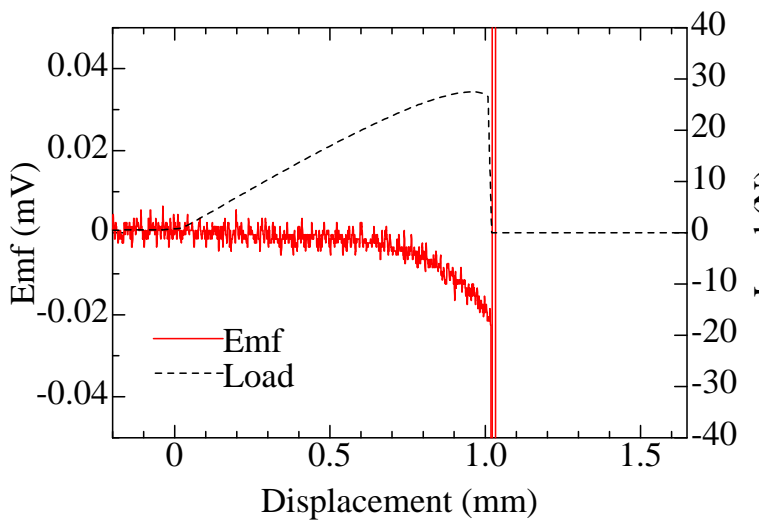

(a)

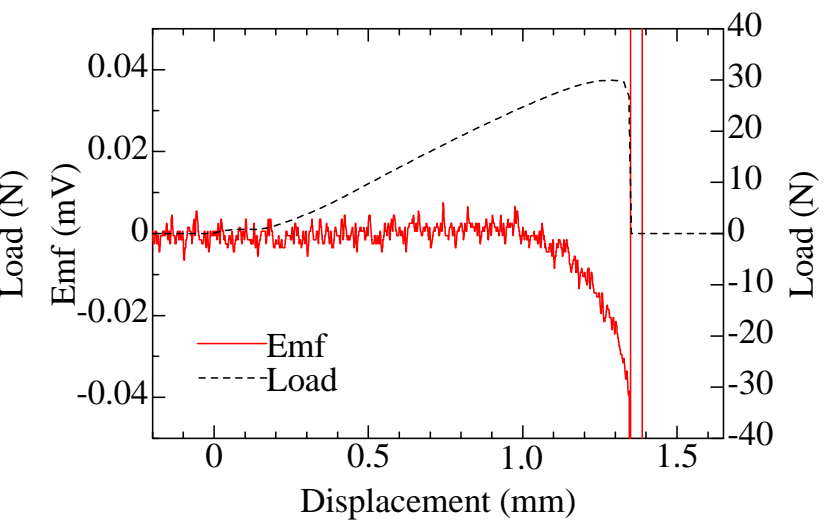

(b)

Fig.4 Emf and load - displacement curves by tensile speeds of (a) $2.0 \mathrm{~mm} / \mathrm{s}$ and (b) $4.0 \mathrm{~mm} / \mathrm{s}$ (SAC) 


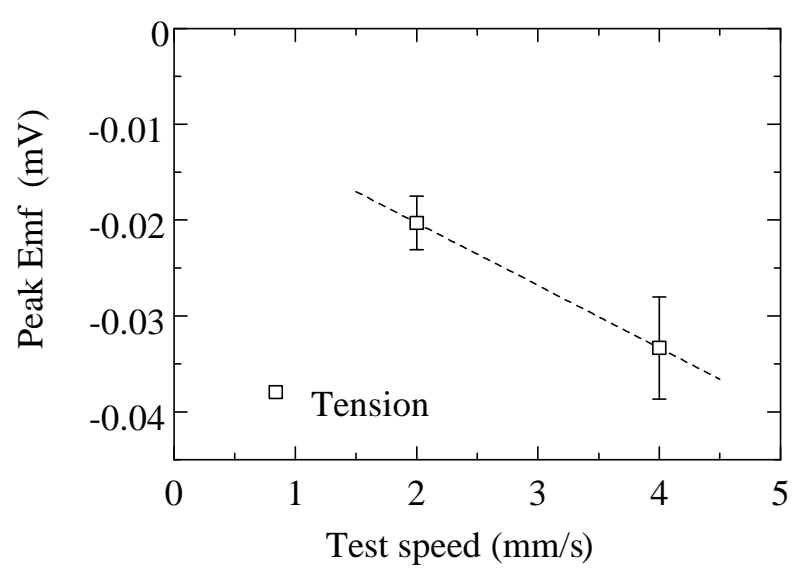

Fig.5 Change of peak Emfs with tensile test speed

(SAC)

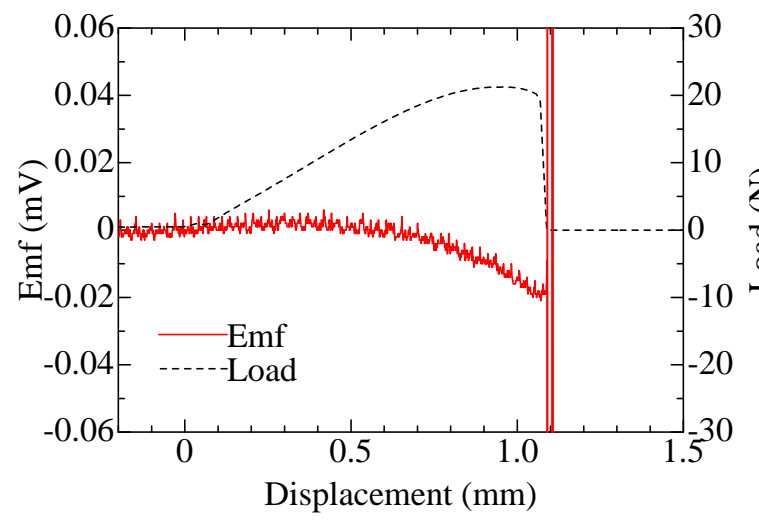

(a)

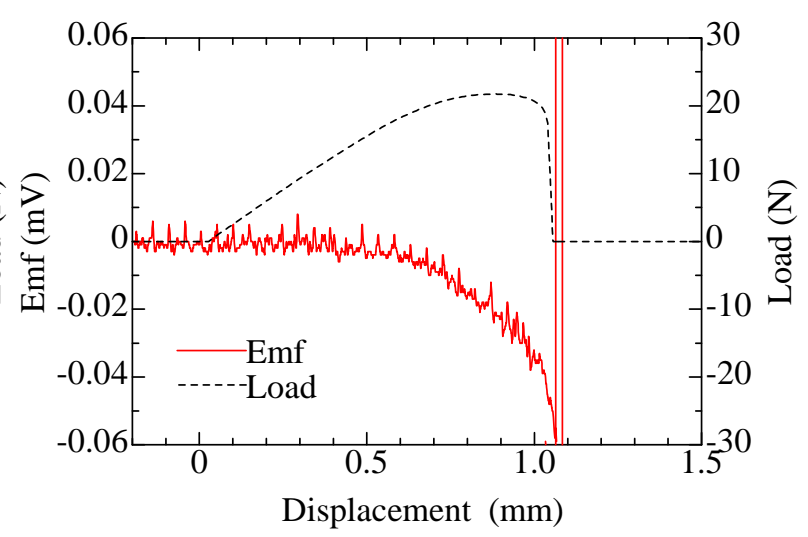

(b)

Fig.6 Emf and load - displacement curves by tensile speeds of

(a) $2.0 \mathrm{~mm} / \mathrm{s}$ and (b) $4.0 \mathrm{~mm} / \mathrm{s} \quad(\mathrm{SP})$

Figure 5 shows peak (= minimum) values of Emf obtained at speeds of $2 \mathrm{~mm} / \mathrm{s}$ and $4 \mathrm{~mm} / \mathrm{s}$. These results agree with the velocity dependency on solder ball compression [6].

Electromotive force in the SP solder joint. Figure 6 shows obtained Emf and load for SP solder joints at speeds of $2 \mathrm{~mm} / \mathrm{s}$ and $4 \mathrm{~mm} / \mathrm{s}$ in tension. The joint is fractured slightly at a little after reaching the maximum load. The Emf starts to decrease considerably after increasing the load, i.e., starting time of the decrease is delayed.

\section{Deformation of solder ball joints by shear loading}

Deformation of SAC solder ball joint. The solder jointed ball is sheared using a small type machine with a shearing jig (Fig.2). This machine is a screw type loading machine which has a capacity of 50N. An L-type jig with a bonded constantan wire is fixed with a loading cross head. The substrate with a solder ball jointed is fixed in a vacuum holding stand. A magnification scope is used to properly position the jig head on the upper side of the testing solder ball.

When the tensile test starts and the jig makes contact with the solder ball, a circuit composed of the constantan wire - jig - solder ball - copper line on the substrate is formed and it is possible to measure generated Emf. Noises are suppressed from the machine, achieving electric isolation between the jig and the whole machine body. 
The obtained Emf data and load when SAC jointed balls are sheared at speeds of $2 \mathrm{~mm} / \mathrm{s}$ and $4 \mathrm{~mm}$ /s are shown in Fig.7. The load continues to increase after yielding and reaches a maximum. The final displacement at speed of $4 \mathrm{~mm} / \mathrm{s}$ is larger than that at $2 \mathrm{~mm} / \mathrm{s}$. The Emf starts to decrease while the load also begins to increase. The Emf has the minimum value at the moment of fracture. By increasing deformation speed from $2 \mathrm{~mm} / \mathrm{s}$ to $4 \mathrm{~mm} / \mathrm{s}$, the minimum Emf decreases.

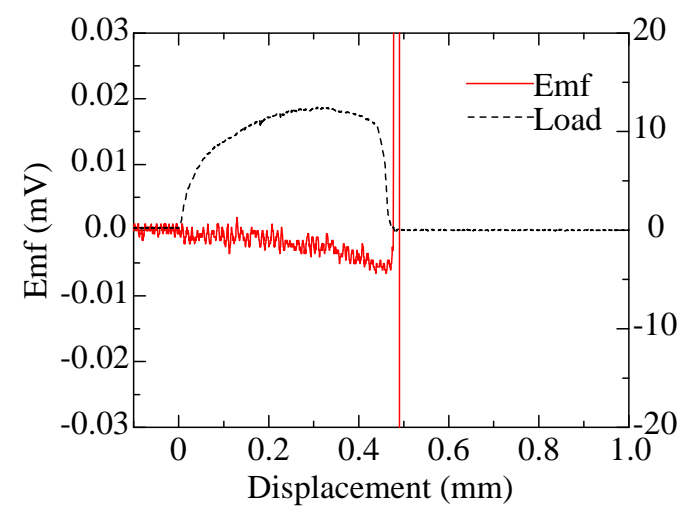

(a)

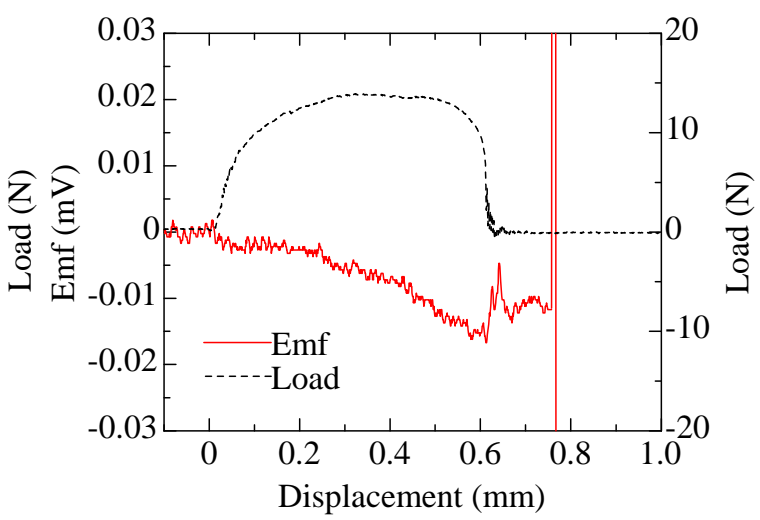

(b)

Fig.7 Emf and load - displacement curves by shear speeds of (a) $2.0 \mathrm{~mm} / \mathrm{s}$ and (b) $4.0 \mathrm{~mm} / \mathrm{s}$ (SAC)

Electromotive force in the SP solder ball joint. The Emf-displacement curve and load-displacement curve of SP by shearing at speeds of $2.0 \mathrm{~mm} / \mathrm{s}$ and $4.0 \mathrm{~mm} / \mathrm{s}$ are shown in Fig. 8 . The load increases rapidly at first and reaches a maximum load. A large displacement is observed until fracture, as demonstrated by the considerable amount of plastic deformation. The Emf is generated with loading and decreases according to the progress of displacement. However, the Emf has a minimum value even after the maximum load and it changes reversely to increase until the breaking point. It is understood that increment of the Emf is due to heat generation by plastic deformation. The Emf change at the speed of $4 \mathrm{~mm} / \mathrm{s}$ becomes clear and the minimum value of Emf is large, compared with the minimum Emf at the speed of $2 \mathrm{~mm} / \mathrm{s}$. The obtained data of maximum Emf of shear at the speed of $2 \mathrm{~mm} / \mathrm{s}$ and $4 \mathrm{~mm} / \mathrm{s}$ are plotted in Emf-deformation speed diagram ofFig.9. The peak Emf at shear decreases as displacement speed increases. The tensioned data in Fig.5 is also shown in Fig.9. The Emfs of both tensile and shear tests decrease similarly as

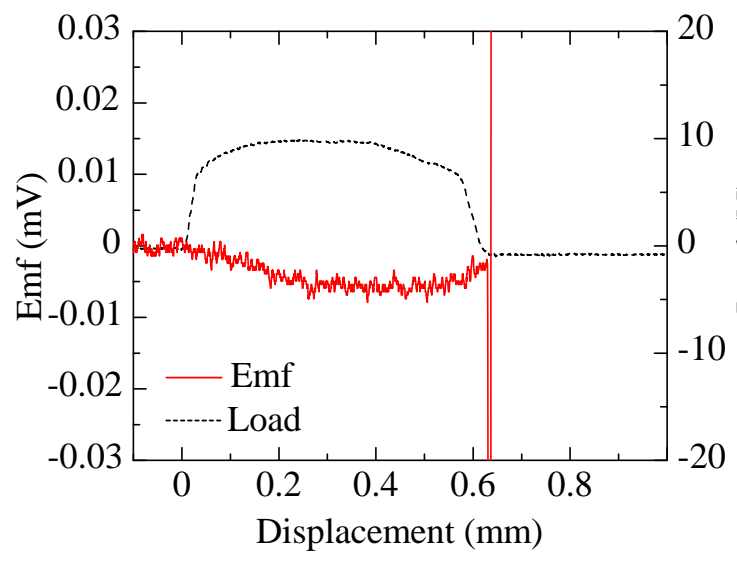

(a)

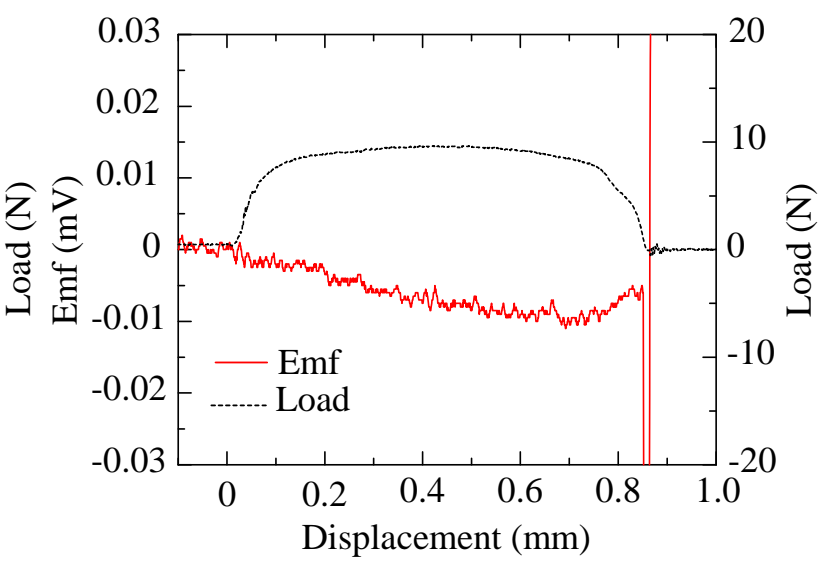

(b)

Fig.8 Emf and load - displacement curves by shear speeds of (a) $2.0 \mathrm{~mm} / \mathrm{s}$ and (b) $4.0 \mathrm{~mm} / \mathrm{s}$ (SP) 


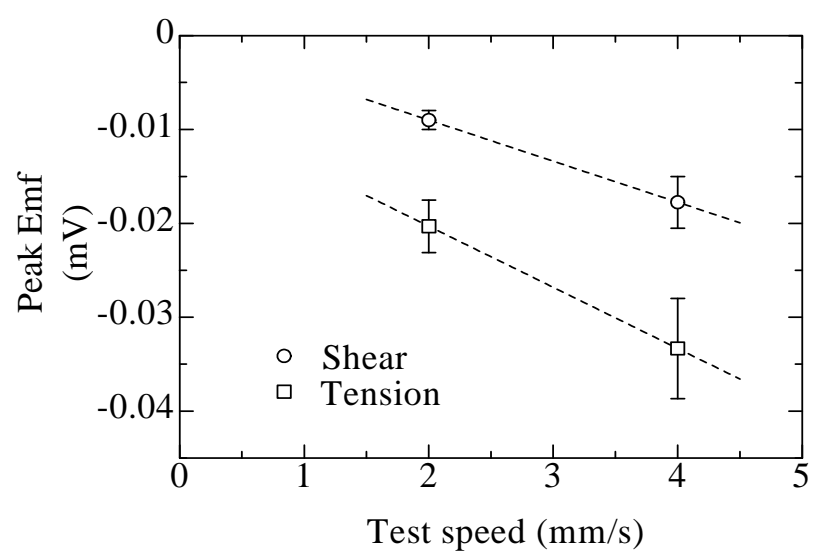

Fig.9 Comparison of Emfs by shear and tension tests (SAC)

deformation speed increases. But the absolute maximum Emf values at tension are larger than those at shear. These differences between Emfs at tension and shear might be the result of strength difference. This difference is clear from the comparison data; that is, the maximum load (30 N) of tension is larger than that of shear $(14 \mathrm{~N})$ for lead-free solder at the speed of $2 \mathrm{~mm} / \mathrm{s}$. In this experiment, the absplute maximum Emf value in the non-lead solder was smaller than the Emf value in the lead-solder.

\section{Conclusions}

Deformation of solder ball joints was studied by the electromotive force technique, which was successfully combined with a conventional testing machine. The conclusions were as follows.

1 The Emf-displacement curve and load-displacement curve of small solder joints were measured effectively at the same time during deformation by tensile and shear forces.

2 The Emfs, i.e., strain energy change, were considerably late in beginning compared with start of load increase.

3 The solder joints were weaker in shear load, compared with tensile load, based on evaluation from the strain energy.

4 The maximum absolute Emf value in the non-lead solder was smaller than the Emf value in the lead-solder.

\section{References}

[1] T. Kumazawa and N. Nakayama, Advances in Experimental Mechanics, MacGraw-Hill, 611-612, 2004.

[2] Chronological Scientific Tables (in Japanese), Maruzen Co., Ltd., 2006.

[3] T. Kumazawa, N. Nakayama, N. Ito, K. Tsubone and M. Abe, Generation of Electromotive Force of Solder Wires and Solder Joints Caused by Their Deformation and its Evaluation (in Japanese), J. Japan Inst. Electron. Packaging,9, 6, 479-484, 2006.

[4] An operator's guide for DAGE series 4000 ver.3, DAGE Precision Industries, 2000.

[5] N. Harwood and W.M. Cummings, Thermo-elastic Stress Analysis, Adam Hilger, 35-70,1991.

[6] T. Kumazawa and S. Komazaki, Deformation evaluation of a small solder ball by electromotive force, Trans. of the Japan Society of Mechanical Engineers, 68, 669, 840-845, 2002. 